\title{
Primary care Physicians' perspective on the management of anxiety and depressive disorders: a cross-sectional survey in Emilia Romagna Region
}

Federica Casini ${ }^{1}$, Cecilia Sighinolfi ${ }^{1}$, Paola Tedesco ${ }^{1}$, Pier Venanzio Bandieri ${ }^{2}$, Maria Bologna ${ }^{3}$, Niccolò Colombini ${ }^{4}$, Clara Curcetti ${ }^{5}$, Michele Magnani ${ }^{1}$, Mara Morini ${ }^{6}$, Alberto Serio ${ }^{7}$, Ilaria Tarricone ${ }^{1}$, Domenico Berardi ${ }^{1}$ and Marco Menchetti ${ }^{*}$

\begin{abstract}
Background: Evidences from literature suggest that Primary Care Physicians' (PCPs) knowledge and attitude about psychological and pharmacological treatments of anxiety and depressive disorders could influence their clinical practice. The aim of the study is double: 1) to assess PCPs' opinions about antidepressants (ADs) and psychotherapy for the management of anxiety and depressive disorders; 2 ) to evaluate the influence of PCPs' gender, age, duration of clinical practice, and office location on their opinions and attitudes.

Methods: This cross-sectional multicentre survey involved 816 PCPs working in four Local Health Units of the Emilia Romagna Region. Participating PCPs were asked to complete a questionnaire during educational meetings between October 2006 and December 2008.

Results: The response rate was 65.1\%. Eighty-five percent of PCPs agreed on the effectiveness of ADs for depressive disorder whereas lower agreement emerged for anxiety disorder and on psychotherapy for both anxiety and depression. Forty percent of PCPs reported to feel "very/extremely confident" in recognizing depression and 20.0\% felt equally confident in treating it with pharmacotherapy. Considering anxiety disorder, these proportions increased. Female PCPs and those located in the rural/mountain areas reported to adopt more psycho-educational support compared to male and suburban colleagues.
\end{abstract}

Conclusions: Our results suggest that an effort should be made to better disseminate recent evidences about the management of anxiety and depressive disorders in Primary Care. In particular, the importance of psychological interventions and the role of drugs for anxiety disorder should be addressed.

Keywords: Anxiety, Depression, Primary care, Antidepressants, Psychotherapy

\section{Background}

Anxiety and depressive disorders are highly prevalent in the general population [1] and associated with disability and low quality of life $[2,3]$. Patients suffering from these conditions are usually treated by Primary Care Physician (PCP) while referral to mental health specialist should be considered for severe cases. Patients prefer to receive care

\footnotetext{
* Correspondence: marco.menchetti3@unibo.it

'Institute of Psychiatry, University of Bologna, Viale C. Pepoli 5, IT-40123

Bologna, Italy

Full list of author information is available at the end of the article
}

from a regular family doctor into a trusting relationship and to avoid stigma related to mental health services access [4]. However, despite several evidence-based treatments for anxiety and depression are available $[5,6]$, their application in the Primary Care setting has been troublesome. Although recent studies showed an increased number of PCPs using antidepressants (ADs) [7], other investigations found that only a minority of Primary Care attenders with anxiety and depressive disorders meeting DSM-IV criteria, were receiving appropriate pharmacological treatment [8,9]. Indeed, 
psychological interventions are rarely delivered in this setting [9].

Different factors can be assumed to explain low rates of treatments, including patients' opinions and preferences [10], under recognition of mental disorders [11], and, with regards to psychological interventions, limited availability of trained physicians [12,13], poor confidence by PCPs $[9,14]$, and time constraints due to the setting $[15,16]$. It is possible that PCPs' knowledge and attitude about treatments, also play an important role, but very few studies have investigated this issue. Aims of the present study are:

1) to assess PCPs' opinions, knowledge and attitudes about the management of anxiety and depressive disorders;

2) to evaluate differences among PCPs subgroups and in particular comparing by gender, age, duration of clinical practice, and office location.

Assuming that a negative attitude or poor knowledge about treatments can diminish the chance to deliver it or to refer patients to the specialist, data from this research could allow the identification of specific educational needs and therefore the organization of tailored PCPs training on mental health issues.

\section{Methods}

\section{Study design}

The present cross-sectional survey was promoted by the Emilia Romagna Regional Programme "G. Leggieri" for the integration between Primary Care and Mental Health $[17,18]$. Emilia Romagna is a Northern Italian Region with, approximately, 4.405.500 inhabitants. It is sectored into 11 Local Health Units, with a Primary Care Department and a Mental Health Department each. To date, 3138 PCPs work in the Region. Four out of 11 Local Health Units of the Region (Bologna, Modena, Reggio Emilia, Rimini) were involved in the present study between October 2006 and December 2008. In order to avoid any kind of influence on PCPs practice, no specific education courses about depression and anxiety treatments were provided during the recruitment period.

PCPs were enrolled during psychiatric educational meetings organized by the Regional Programme "G. Leggieri". This survey was authorized by the Primary Care Departments of the four Local Health Units involved and the steering committee of the Regional Programme "G. Leggieri". These meetings were mandatory for PCPs as part of their continuous education programme. Each participant physician received the Common Mental Disorders Questionnaire and the Depression Attitude Questionnaire [19] with a cover letter explaining the aims of the study. Questionnaires were anonymous and participation in the survey was voluntary.

\section{Common mental disorders questionnaire (CMDQ)}

"Common Mental Disorders" expression, indicates a not severe subgroup of anxious-depressive disorders, which frequently affected general population (almost 1 person on 5) and that are often managed in Primary Care. A team work including a psychologist (F.C.), a psychiatrist (M.M.) and a PCP (A.S.), developed an ad-hoc, selfreported questionnaire: the CMDQ aimed to investigate PCPs' opinions and attitude toward patients with anxiety and depressive disorders.

The questionnaire is divided in 4 sections focus on the following areas:

1) PCPs' individual characteristics: age, gender and professional details (previous specialization, years of clinical practice, numbers of attenders, group or solo practice, educational initiatives about Mental Health topics attended).

2) Opinions, confidence and self-reported clinical behaviour in the management of patients: personal confidence in dealing with anxiety and depressive disorders, considering relation with patients, diagnosis, pharmacological and psychological treatments. PCPs' opinion about ADs and psychotherapy effectiveness, and the treatment they usually provided.

3) Collaboration with Mental Health Services: degree of satisfaction, opinions about obstacles and preference on type on collaboration with Mental Health professionals.

4) Perceived needs for education and training on psychiatric issues: estimation of PCPs' own skills in managing anxiety and depressive disorders.

It was explained that "psychological interventions" is referred to psychotherapy, counselling and psychological support at general. Some others items instead were referred to "psychological interventions" at general, and others were specific for different interventions.

A 5-points Likert scale with score anchors of "strongly disagree/strongly agree" "not at all satisfied/completely satisfied", measured each items; multiple choice questions were also presented.

\section{Depression attitude questionnaire (DAQ)}

The DAQ [19] is a self-completion instrument comprising 20 statements about depression, concerning aetiology, course, treatment options, and role of the PCP, mental health specialist and nurse. Answers to each item are marked on a $100 \mathrm{~mm}$ visual analogue scale between "strongly disagree" (0 $\mathrm{mm})$ and "strongly agree" 
(100 mm). The questionnaire has been used in several countries by various health professionals [20-22] like NHS direct nurses [23], practice nurses [24], district nurses [25], in-patient staff [26] and by psychiatrists [27].

An Italian version of DAQ with a three factor solution has been elaborated [28]. For the purpose of this study, only items $12,13,15,16,17,18,19$ and 20 were considered (Additional file 1).

\section{Data analysis}

PCPs individual characteristics and responses to closed-end items were analysed using general descriptive statistics, including numbers, proportions, means and standard deviations. For ease of presenting the 5-points Likert scales' results were grouped together in three categories: "disagree", "neutral", "agree". With regard to confidence the PCPs' answers were grouped in: "very/extremely unconfident", "neither confident nor unconfident" and "very/extremely confident".

Between-group comparisons were made by gender, age, duration of clinical practice (more or less than 15 years), and the PCP's office location (urban centre $>100.000$ inhabitants, urban centre $<100.000$ inhabitants, suburban, and rural/mountain areas). Comparisons were tested by the Student's t test and one-way analysis of variance (least significant difference, LSD, Bonferroni, post hoc test), and $\mathrm{p}$ values less than or equal to 0.05 were considered statistically significant. For multiple post hoc comparisons assessing the influence of office location (4 subgroups), we adjusted the level of significance at $0.008(0.05 / 6)$.

Statistical Package for the Social Sciences version 15.0 for Windows was used to carry out the analysis [29].

\section{Results}

\section{Participants}

Of the 816 questionnaires distributed, 531 were returned ( response rate $=65.1 \%$ ). The $66.0 \%$ of participants were males and had mean age of $53.7 \pm 5.1$ years (ranging from 29 to 69). Mean duration of clinical practice in Primary Care was $22.0 \pm 8.2$ years (range: 1 to 41 ). Forty point eight percent reported to work in a group practice. The mean number of attenders per PCP was $1281 \pm 358$ (range 85 to 1970) (Figure 1). Seventy-three point four percent of PCPs attended at least one meeting or conference on psychiatric topics in the previous two years.

The most frequent physicians' previous specializations were: Internal Medicine (9.2\%), Geriatrics (7.5\%), Gastroenterology (6.1\%), Paediatrics (6.1\%), General Medicine (5.8\%), Pneumology (5.3\%) and Cardiology (5.1\%). Several other specializations were less frequent than $5.0 \%$. Only $1.2 \%$ of PCPs had a specialization in Psychiatry and $2.2 \%$ in Psychology. Finally, $12.6 \%$ of PCPs reported to have no specialization.

\section{Opinions and confidence towards management}

PCPs strongly agreed on ADs' effectiveness in the treatment of depressive disorder, while opinions about their effectiveness for anxiety disorder and about psychotherapy for both conditions were less consistent (Table 1). Overall, only half of PCPs reported to feel confident in managing depressed patients and the rate of PCPs reporting "very/ extremely" confidence was: $39.3 \%$ in recognition and diagnosis, $20.3 \%$ in pharmacotherapy, and $7.3 \%$ in delivering psychological interventions. With regards to anxiety disorder, these proportions increased to $67.2 \%, 55.1 \%$, $33.9 \%$, and $15.3 \%$, respectively.

From the DAQ answers analysis, $27.4 \%$ of PCPs thought it was rewarding to spend time looking after depressed patients (DAQ Item 15), and 92.9\% strongly agreed with the statement "working with depressed patients is heavy going" (DAQ Item 13). Regarding the roles of PCPs and psychiatrists, $56.1 \%$ of PCPs strongly disagreed with the statement "if depressed patients need antidepressants, they are better off with a psychiatrist than with a general practitioner" (DAQ Item 17), and 68.0\% of them stated that psychotherapy should be left to a specialist (DAQ Item 19). Only 20.0\% of physicians considered psychotherapy not effective for depression (DAQ Item 16), and $37.0 \%$ of PCPs agreed with the statement "if psychotherapies were more easily accessible, they would be more beneficial than drugs for most of the patients" (DAQ Item 20).

\section{PCPs' clinical behaviour}

PCPs managed an average of $66.3 \%$ of patients suffering from anxiety and depressive disorders, while $32.6 \%$ are referred to a specialist. Pharmacotherapy was the intervention most frequently delivered by PCPs in the treatment of anxiety and depressive disorders (93.0\%), followed by psycho-education (67.4\%), generic psychological support (56.1\%), and family intervention (33.2\%). Structured psychological interventions such as counselling, behavioural intervention and problem solving were rarely provided (15.8\%, $11.9 \%$ and $6.2 \%$ respectively).

\section{Comparisons by gender, age, years of practice, and office location}

In comparison by gender, female often adopted psychoeducation and environmental support, as well as pharmacological treatment. Compared to their male colleagues they felt less confident in treating depressive and anxiety disorders and perceived their knowledge in recognition, diagnosis and treatment of these disorders as less adequate (Table 2).

Comparisons by PCPs' office location are showed in Table 3. Physicians working in rural/mountain areas, delivered more psychological support than those in suburb areas $\left(x^{2}=8.245, \mathrm{df}=1, \mathrm{p}=0.004\right)$. Moreover, a higher 


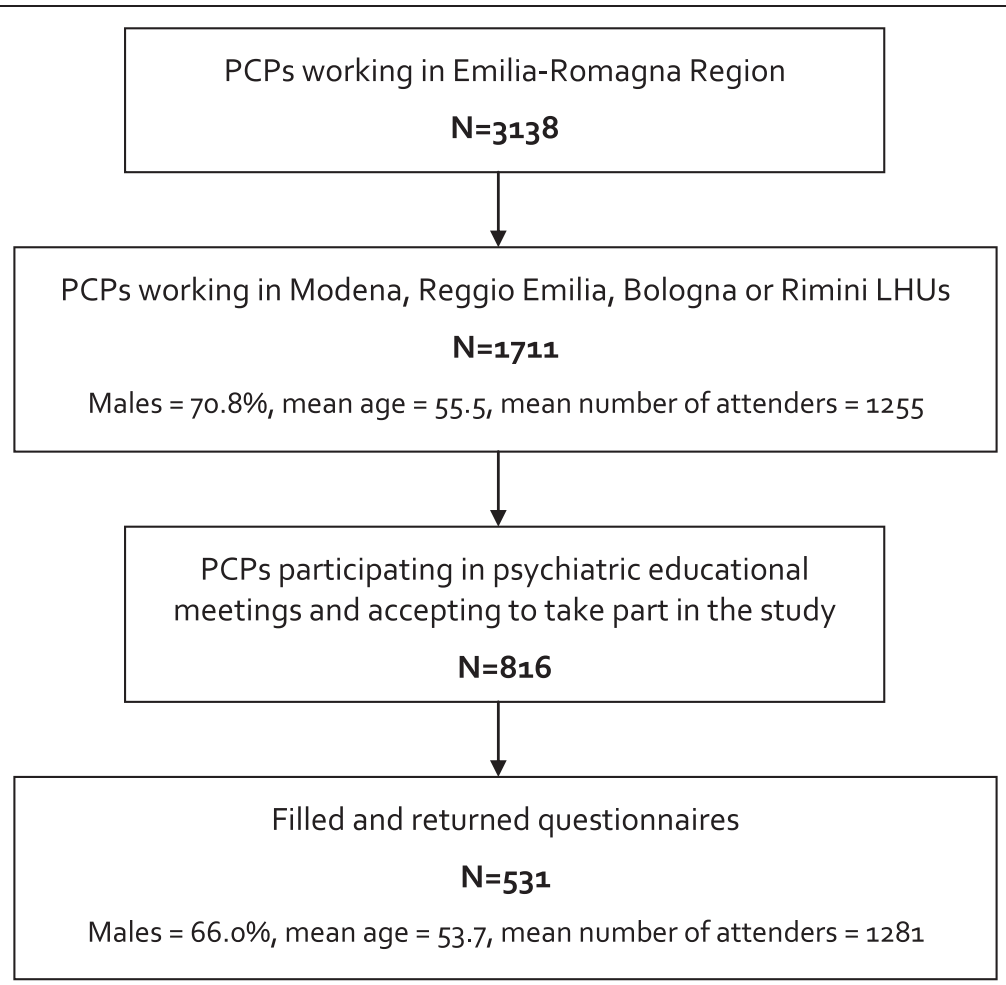

Figure 1 Flow diagram of the study.

percentage of PCPs working in rural/mountain area and urban centres with $<100.000$ inhabitants supported ADs effectiveness in the treatment of anxiety disorders compared to their colleagues working in urban areas $\left(x^{2}=12.462, \mathrm{df}=2, \mathrm{p}=0.002\right.$ and $\mathrm{X}^{2}=13.737, \mathrm{df}=2$, $\mathrm{p}=0.001$, respectively). Similar findings were found for ADs effectiveness in the treatment of depressive disorder without reaching the statistical significance.

No differences were found in the comparison by age of PCPs and duration of clinical practice with regards to opinions, self-confidence, and clinical behaviour.

\section{Discussion}

Despite the key role PCPs play in the management of anxiety and depressive disorders, only few information are available on their knowledge and attitude toward the treatment of these disorders. Aim of the present study was to assess the above issues in a large and representative sample of 531 PCPs working in a Northern Italy region.
To our knowledge this investigation is the first allowing a direct comparison between PCPs' answers on both anxiety and depressive disorders and thus it can evaluate differential educational needs for these two major diagnostic categories.

Regarding depressive disorders, the large majority of PCPs showed to rely on ADs' effectiveness, while less than a half considered psychotherapy as effective. However, only about 1 out of 5 of the interviewed physicians, believed that psychotherapy is not effective for depression, indicating a general positive opinion toward psychological treatments. About $37.0 \%$ of PCPs thought that if psychotherapies were more easily accessible, it would be more beneficial than drugs for most patients. Our data are in line with previous studies reporting that many PCPs considered ADs as effective and sufficient in most cases and psychotherapy as a completion of treatment $[15,20]$. Andersson [30] stated that all PCPs interviewed agreed with the statement "for

Table 1 PCP's opinions about effectiveness of antidepressants and psychotherapy for treatment of anxiety and depressive disorders

\begin{tabular}{lcccc}
\hline Statement & $\begin{array}{c}\text { AD is effective for } \\
\text { depressive disorder }\end{array}$ & $\begin{array}{c}\text { Psychotherapy is effective } \\
\text { for depressive disorder }\end{array}$ & $\begin{array}{c}\text { AD is effective } \\
\text { for anxiety disorder }\end{array}$ & $\begin{array}{c}\text { Psychotherapy is effective } \\
\text { for anxiety disorder }\end{array}$ \\
\hline Disagree & 2.3 & 18.3 & 13.6 & 12.5 \\
Neutral & 12.5 & 33.5 & 34.8 & 26.1 \\
Agree & $\mathbf{8 5 . 3}$ & $\mathbf{4 8 . 2}$ & $\mathbf{5 1 . 5}$ & $\mathbf{6 1 . 4}$ \\
\hline
\end{tabular}


Table 2 PCPs' socio-demographic characteristics and opinions: comparison by PCPs' gender

\begin{tabular}{|c|c|c|c|}
\hline & \multicolumn{2}{|c|}{ Gender } & \multirow{2}{*}{$\begin{array}{c}\text { Statistics } \\
\left(\chi^{2} / \mathbf{F}, \mathbf{d f}, \mathbf{p}\right)\end{array}$} \\
\hline & Male & Female & \\
\hline Age, mean (sd) & $55.0(4.8)$ & $51.2(4.8)$ & $59.902,1,<0.001$ \\
\hline Medical practice, years, mean (sd) & $23.8(7.9)$ & $18.6(7.9)$ & $49.488,1,<0.001$ \\
\hline Number of patients, mean (sd) & $1332.5(325.7)$ & $1184.7(398.7)$ & $19.873,1,<0.001$ \\
\hline \multicolumn{4}{|l|}{ Intervention } \\
\hline Psychoeducation, \% & 63.8 & 74.2 & $4.213,1,0.040$ \\
\hline Psychopharmacology, \% & 93.7 & 91.4 & $0.682,1,0.409$ \\
\hline Behavioural, \% & 13.0 & 10.2 & $0.667,1,0.414$ \\
\hline Problem solving, $\%$ & 7.5 & 3.9 & $1.870,1,0.171$ \\
\hline Counselling, \% & 16.2 & 15.6 & $0.021,1,0.884$ \\
\hline Psychological support ,\% & 54.2 & 60.2 & $1.245,1,0.264$ \\
\hline Family intervention, $\%$ & 29.6 & 39.8 & $3.995,1,0.046$ \\
\hline \multicolumn{4}{|l|}{ Effectiveness of ADs } \\
\hline Depressive disorders, agree $\%$ & 86.2 & 83.2 & $0.866,2,0.649$ \\
\hline Anxiety disorders, agree $\%$ & 50.7 & 52.5 & $0.163,2,0.922$ \\
\hline \multicolumn{4}{|l|}{ Effectiveness of psychotherapy } \\
\hline Depressive disorders, agree $\%$ & 48.0 & 49.2 & $0.539,2,0.764$ \\
\hline Anxiety disorders, agree $\%$ & 56.4 & 71.5 & $11.45,2,0.003$ \\
\hline \multicolumn{4}{|l|}{ Confidence in the management } \\
\hline Depressive disorders, very/extremely confident $\%$ & 53.7 & 39.5 & $7.133,2,0.028$ \\
\hline Anxiety disorders, very/extremely confident $\%$ & 71.6 & 58.9 & $6.366,2,0.041$ \\
\hline Adequate knowledge on CMD diagnoses, agree \% & 47.9 & 36.5 & $4.683,2,0.096$ \\
\hline Adequate knowledge on CMD treatment, agree \% & 43.0 & 29.6 & $6.987,2,0.030$ \\
\hline DAQ $15 \mathrm{M}(\mathrm{SD})$ & $49.0(29.3)$ & $42.4(25.1)$ & $6.446,1,0.011$ \\
\hline
\end{tabular}

List of abbreviations: PCP Primary Care Physician, ADs Antidepressant Drugs, CMD Common Mental Disorder, DAQ Depression AttitudeQuestionaire. Note: Only $D A Q$ items showing a statistical significance in the comparison were presented.

patients with Major Depression, psychotherapy cannot replace drug treatment".

Regarding anxiety disorder a higher proportion of physicians relied on psychotherapy, while less agreement on ADs effectiveness was reported. PCPs might perceive anxiety disorder as less severe than depression, thus not needing pharmacotherapy.

In general, our data show that evidence based recommendations for the management of depressive and anxiety disorders $[5,6]$ were not completely adopted by PCPs. As other studies conducted in Primary Care clearly proved, psychological interventions for Major Depression are highly effective, being superior to usual PCPs' care and comparable to ADs [31,32]. Therefore, the underestimation of psychotherapy effectiveness become problematic in Primary Care because mild forms of depression are common and psychological interventions are essential for patients at low risk-benefit ratio with drugs such as old people, severe physically ill, pregnant women, etc.
Regarding confidence towards management, $49.0 \%$ and $67.2 \%$ of PCPs reported to be confident in the recognition and diagnosis of depressive and anxiety disorders, respectively. In contrast with Richards et al.'s [14] study, reporting a high proportion of PCPs feeling "most/very confident" in treating depression with drugs, our data show that only $20.3 \%$ of PCPs felt "very/extremely" confident in delivering pharmacotherapy for depression. The availability of welltolerated drugs and their frequent use in Primary Care demonstrated by pharmaco epidemiological data [33], makes the results not easy to understand. Although the pharmacological treatment was the most delivered in our sample, only a minority of PCPs expressed full confidence about ADs. As expected and in line with literature [9,34], PCPs did not seem as keen on recurring to psychological treatments and a very low rate of physicians felt very confident with them. There are several factors that could determinate a scarce use of psychological interventions in Primary Care, such as limited time of consulting [35], PCPs' inadequate training on non-pharmacological 
Table 3 PCPs' socio-demographic characteristics and opinions: comparison by PCPs' office location

\begin{tabular}{|c|c|c|c|c|c|}
\hline & $\begin{array}{c}\text { Urban centre } \\
>100.000\end{array}$ & Suburb area & $\begin{array}{l}\text { Rural/Mountain } \\
\text { area }\end{array}$ & $\begin{array}{c}\text { Urban centre } \\
<100.000\end{array}$ & $\begin{array}{c}\text { Statistics } \\
\left(\mathrm{x}^{2} / \mathrm{F}, \mathrm{df}, \mathrm{p}\right)\end{array}$ \\
\hline Age, mean (sd) & $54.0(5.0)$ & $53.9(4.3)$ & $52.9(6.0)$ & $53.8(5.3)$ & $0.927,3,0.428$ \\
\hline Medical practice, years, mean (sd) & $22.3(8.4)$ & $22.2(7.8)$ & $20.8(8.8)$ & $22.4(7.9)$ & $0.889,3,0.447$ \\
\hline Number of patients, mean (sd) & $1252.0(375.2)$ & $1341.7(306.1)$ & $1295(337.5)$ & $1273.0(386.7)$ & $1.491,3,0.216$ \\
\hline \multicolumn{6}{|l|}{ Intervention } \\
\hline Psychoeducation, \% & 65.6 & 70.7 & 72.7 & 61.4 & $3.528,3,0.317$ \\
\hline Psychopharmacology, \% & 93.3 & 90.2 & 91.9 & 96.0 & $2.694,3,0.441$ \\
\hline Behavioural, \% & 14.4 & 16.3 & 10.2 & 7.9 & $3.991,3,0.262$ \\
\hline Problem solving, $\%$ & 10.0 & 6.5 & 6.1 & 3.0 & $3.998,3,0.262$ \\
\hline Counselling, \% & 15.6 & 18.5 & 16.3 & 13.9 & $0.785,3,0.853$ \\
\hline Psychological support, \% & 56.7 & 45.7 & 66.3 & 54.5 & $8.348,3,0.039$ \\
\hline Family intervention, \% & 32.2 & 30.4 & 32.7 & 35.6 & $0.619,3,0.892$ \\
\hline \multicolumn{6}{|l|}{ Effectiveness of ADs } \\
\hline Depressive disorders, agree $\%$ & 81.9 & 83.7 & 90.6 & 88.6 & $12.445,6,0.053$ \\
\hline Anxiety disorders, agree \% & 44.0 & 49.5 & 59.4 & 58.1 & $21.207,6,0.002$ \\
\hline \multicolumn{6}{|l|}{ Effectiveness of psychotherapy } \\
\hline Depressive disorders, agree \% & 49.5 & 46.2 & 51.9 & 44.2 & $3.0318,6,0.805$ \\
\hline Anxiety disorders, agree \% & 63.3 & 59.6 & 57.5 & 64.4 & $5.849,6,0.440$ \\
\hline \multicolumn{6}{|l|}{ Confidence in the management } \\
\hline Depressive disorders, very/extremely confident \% & 48.9 & 51.1 & 54.9 & 41.3 & $8.003,6,0.238$ \\
\hline Anxiety disorders, very/extremely confident $\%$ & 66.7 & 63.3 & 72.5 & 66.3 & $7.569,6,0.271$ \\
\hline Adequate knowledge on CMD diagnoses, agree \% & 46.1 & 38.5 & 50.0 & 41.7 & $4.682,6,0.585$ \\
\hline Adequate knowledge on CMD treatment, agree $\%$ & 36.0 & 36.3 & 45.5 & 36.3 & $3.771,6,0.708$ \\
\hline DAQ $12 \mathrm{M}(\mathrm{SD})$ & $50.8(27.7)$ & $52.3(28.9)$ & $66.4(23.9)$ & $56.09(28.1)$ & $8.087,3,<0.001$ \\
\hline DAQ $16 \mathrm{M}(\mathrm{SD})$ & $36.2(27.8)$ & $41.3(26.5)$ & $36.2(26.9)$ & $46.19(29.5)$ & $3.523,3,0.015$ \\
\hline DAQ $19 \mathrm{M}(\mathrm{SD})$ & $71.5(27.5)$ & $76.4(26.6)$ & $65.0(27.9)$ & $71.61(26.8)$ & $3.034,3,0.029$ \\
\hline
\end{tabular}

List of abbreviations: PCP Primary Care Physician, ADs Antidepressants Drugs, CMD Common Mental Disorder, DAQ Depression Attitude Questionnaire. Note: Only $D A Q$ items showing a statistical significance in the comparison were presented.

interventions [36,37] and PCPs' attitudes and opinions on psychotherapy $[15,16,20]$. Indeed, in our study the majority of family practitioners agreed with the statement "psychotherapy for depressed patients should be left to specialists" (DAQ Item 19), suggesting that PCPs consider psychological interventions not completely part of their duty and that they should be carried out by specialists.

Our data show that family medicine education could benefit from specific tailored training on diagnosis and treatment of anxiety and depressive disorders in order to increase their perceived confidence in the management of these patients. In particular, it seems crucial to provide training on psychological interventions suited to Primary Care setting. In a previous study, it was demonstrated that a practical evidence-based counselling intervention could feasibly be taught during PCPs training and that trainees found it helpful in their future practices [38].

Considering comparisons, PCPs working in rural/ mountain areas and female PCPs reported to adopt more frequently non-pharmacological treatments, as psycho-education, psychological support and family intervention, than urban areas and male PCPs. Indeed, a higher proportion of female doctors, compared to male colleagues, agreed that psychotherapy is an effective treatment for anxiety disorder. Our results are consistent with the few previous studies investigating both attitude and clinical behaviour according to office location and gender $[14,39]$. The more frequent use of psychological interventions reported by rural PCPs could be explained by the limited accessibility to mental health services in their area. It is possible that they decided to personally treat these patients including psychological aspects [40]. This might be consistent with the relatively higher confidence reported by rural PCPs on recognition, ADs and doctor-patient relationship, for both anxiety and depressive disorders, compared to colleagues in suburb and urban areas. Also, the prevalence of depression is higher in rural than in urban areas, probably because rural 
population tends to have characteristics that are strongly associated with depression, including poor health status, chronic disease, and poverty [41]. Therefore, rural PCPs are more likely to treat depressed patients, acquiring experience and becoming confident with this disorder.

With regards to gender differences, consistently with literature, our findings show that female physicians tend to spend more time with patients $[42,43]$, pay more attention to relational aspects of care [44] and to be more likely to engage in counselling and conversations about social and family issues, compared to male physicians who seemed to pay more attention to technical aspects of care (physical examinations) [39,43]. A previous Italian study was in line with our results: female PCPs provide a higher number of follow-up visits for mild and stabilized cases which mainly required clinical monitoring [45]. Other studies in different settings show that women have higher odds of being less confident in identifying and managing medical conditions compared to men $[40,46,47]$. Similarly in our study, female PCPs reported to feel less confident in managing depressive and anxiety disorders and they perceived their knowledge about recognition and treatment of anxiety and depression less adequate than men. They also reported that evidence-based guidelines influenced their clinical practice [48]. So we suppose that guidelines' higher influence on female PCPs, led them having a high critical perception of their knowledge on psychiatric issues. Particularly, they could be better aware about psychotherapy effectiveness for mild depressive and anxiety disorders and were not able to deliver "psychological intervention" after family medicine education.

\section{Limitations}

This study has some limitations that may affect the generalizability of results. The socio-demographic and practice characteristics of the sample are comparable to regional PCPs population (personal communications by the four participating Primary Care departments). However, it is not possible to generalize these results to other countries with different healthcare organization or to whole Italian Primary Care: the Emilia Romagna Region is one of wealthiest area of Italy and has a well organized and developed health care system with a specific program to integrate Primary Care and Mental Health services [18]. Despite the high response rate, there might still be a non-response bias; the participation was asked during mandatory educational initiatives but PCPs can refuse to entry in the study. So physicians with poor interest in mental health issue and/or those with little or no confidence in management of mental disorders might have chosen not to participate, hence possibly overestimate our findings on comfort. However, our data showed low confidence rates and thus we think that this bias do not affect extensively our findings.
This study was based on a self-report investigation and did not evaluate PCPs clinical behaviour by objective measures. The relationship between opinions/attitudes and clinical behavior is controversial. Some studies suggested that attitude can affect the management of anxiety and depressive disorders, influencing clinical choice, use of psychological interventions and referral to psychologists [49], while other studies found that opinions are not good predictors of PCPs' clinical practice [50].

We investigated ADs as a drug class and we have no information about the type of $\mathrm{AD}$ and prescribed dose. Considering that in Primary Care setting the average daily doses are usually lower than those recommended for the treatment of the major depression [33], our study does not evaluate the appropriateness of PCPs choice. Moreover, we have no available data on the use of benzodiazepines. Their prescription is very frequent in the Italian Primary Care setting [51,52] and it would be of interest to assess, at the same time, PCPs' opinions and confidence about both ADs and benzodiazepines for the management of anxiety disorders. However, our study protocol did not allow this comparison and this issue requires further research.

There are very few published reliable instruments assessing PCP's opinions, knowledge, and attitudes about mental disorders. An ad-hoc questionnaire was developed and subsequently tested in some pilot surveys to define the most useful items and a final version. We do not evaluate the reliability and the validity of the instrument.

\section{Conclusions}

Our results suggest that an effort should be made to disseminate the most recent evidences on the management of depressive and anxiety disorders in Primary Care during and after the family medicine education. In particular, it should be emphasized the important role of psychological interventions for these disorders. It seems crucial to teach PCPs the basic skills for providing brief structured psychological support and to increase professional PCPs comfort in this area. Results concerning the poor confidence of PCPs in using ADs are unexpected and need further investigations. A qualitative research might be useful to light up on this topic and better address PCPs educational needs. Relevant differences in educational needs were found among PCPs subgroups, especially when analysing the sample by gender and office location. Training initiatives should take into account these differences and tailor adequate programs in order to work on specific point of weakness. For example, male PCPs should benefit to pay attention to psychological skills during continuing medical education. 


\section{Additional file}

\section{Additional file 1: DAQ items.}

\section{Abbreviations}

ADs: Antidepressants; PCPs: Primary Care Physicians.

\section{Competing interest}

The authors declare that they have no competing interests.

\section{Authors' contributions}

MMe, DB, AS and FC conceived and designed the study. FC, CS, PT and MMe analysed and interpreted the data. FC and MMe wrote the first draft of the manuscript. All authors contributed to the critical revision of the manuscript for important intellectual content. All authors read and approved the final manuscript.

\section{Acknowledgements}

The study team wishes to thank Dr. Angelo Fioritti, Mental Health Department AUSL Bologna (former Director Mental Health and Substance Abuse Service, Emilia Romagna Region) and Dr. Angelo Brambilla, Director Service for Health District, Primary Care, Planning and Development of Health Services, Regional Health Care and Social Authority, Emilia Romagna Region. Moreover, thank you to the PCPs who spent their time and help us to assess their opinions, knowledge and attitudes about the management of anxiety and depressive disorders.

\section{Author details}

${ }^{1}$ Institute of Psychiatry, University of Bologna, Viale C. Pepoli 5, IT-40123 Bologna, Italy. ${ }^{2}$ Mental Health Department, Local Health Unit Rimini, Rimini, Italy. ${ }^{3}$ Mental Health Department, Local Health Unit Reggio Emilia, Reggio Emilia, Italy. ${ }^{4}$ Mental Health Department, Local Health Unit Modena, Modena, Italy. ${ }^{5}$ Service for Health District, Primary Care, Planning and Development of Health Services, Regional Health Care and Social Authority, Bologna, Emilia Romagna Region, Italy. ${ }^{6}$ Primary Care Department, Local Health Unit Bologna, Bologna, Italy. ${ }^{7}$ Primary Care Physician of the Local Health Unit Bologna, Bologna, Italy.

Received: 24 February 2013 Accepted: 29 May 2013 Published: 7 June 2013

\section{References}

1. World Mental Health Survey Consortium: Prevalence, severity, and unmet need for treatment of mental disorders in the world health organization world mental health surveys. JAMA 2004, 291(21):2581-2590.

2. Colman SS, Brod M, Potter LP, Buesching DP, Rowland CR: Cross-sectional 7-year follow-up of anxiety in primary care patients. Depress Anxiety 2004, 19(2):105-111.

3. Ansseau M, Fischler B, Dierick M, Albert A, Leyman S, Mignon A: Socioeconomic correlates of generalized anxiety disorder and major depression in primary care: the GADIS II study (generalized anxiety and depression impact survey II). Depress Anxiety 2008, 25(6):506-513.

4. Wun YT, Lam TP, Goldberg D, Lam KF, Li KT, Yip KC: Reasons for preferring a primary care physician for care if depressed. Fam Med 2011, 43(5):344-350

5. National Institute for Health and Clinical Excellence: Depression: the treatment and management of depression in adults. 2009. http://www.nice.org.uk/CG90.

6. National Institute for Health and Clinical Excellence: Generalized anxiety and panic disorder (with and without agoraphobia) in adults. 2011. http://www.nice.org.uk/CG113.

7. Martín-Agueda B, López-Muñoz F, Rubio G, Guerra JA, Silva A, Alamo C: Management of depression in primary care: a survey of general practitioners in Spain. Gen Hosp Psychiatry 2005, 27(5):305-312.

8. Aragonès E, Piñol JL, Labad A, Folch S, Mèlich N: Detection and management of depressive disorders in primary care in Spain. Int J Psychiatry Med 2004, 34(4):331-343.

9. Weisberg RB, Dyck I, Culpepper L, Keller MB: Psychiatric treatment in primary care patients with anxiety disorders: a comparison of care received from primary care providers and psychiatrists. Am J Psychiatry 2007, 164(2):276-282.
10. Van Schaik DJ, Klijn AF, van Hout HP, van Marwijk HW, Beekman AT, de Haan M, van Dyck R: Patients' preferences in the treatment of depressive disorder in primary care. Gen Hosp Psychiatry 2004, 26(3):184-189.

11. Fernández A, Pinto-Meza A, Bellón JA, Roura-Poch P, Haro JM, Autonell J, Palao DJ, Peñarrubia MT, Fernández R, Blanco E, Luciano JV, Serrano-Blanco A: Is major depression adequately diagnosed and treated by general practitioners? Results from an epidemiological study. Gen Hosp Psychiatry 2010, 32(2):201-209.

12. Jaén $C R$, Stange $K C$, Nutting PA: Competing demands of primary care: a model for the delivery of clinical preventive services. J FamPract 1994, 38(2):166-171.

13. Meredith LS, Jackson-Triche M, Duan N, Rubenstein LV, Camp P, Wells KB: Quality improvement for depression enhances long-term treatment knowledge for primary care clinicians. J Gen Intern Med 2000, 15(12):868-877.

14. Richards JC, Ryan P, McCabe MP, Groom G, Hickie IB: Barriers to the effective management of depression in general practice. Aust $N Z \mathrm{~J}$ Psychiatry 2004, 38(10):795-803

15. Andersson SJ, Troein M, Lindberg G: General practitioners' conceptions about treatment of depression and factors that may influence their practice in this area. A postal survey. BMC Fam Pract 2005, 6(1):21.

16. Pierce D, Gunn J: GPs' use of problem solving therapy for depression: a qualitative study of barriers to and enablers of evidence based care. BMC Fam Pract 2007, 25:8-24.

17. Menchetti M, Tarricone I, Bortolotti B, Berardi D: Integration between general practice and mental health services in Italy: guidelines for consultation-liaison services implementation. Int J Integr Care 2006, 6:e05.

18. Rucci P, Piazza A, Menchetti M, Berardi D, Fioritti A, Mimmi S, Fantini MP: Integration between primary care and mental health services in Italy: determinants of referral and stepped care. Int J Family Med 2012, 2012:507464.

19. Botega N, Mann A, Blizard R, Wilkinson G: General practitioners and depression-first use of the depression attitude questionnaire. Int J Methods Psychiatr Res 1992, 2:169-180.

20. Ross S, Moffat K, McConnachie A, Gordon J, Wilson P: Sex and attitude: a randomized vignette study of the management of depression by general practitioners. Br J Gen Pract 1999, 49(438):17-21.

21. Thornett AM, Pickering RM, Willis T, Thompson: Correspondence. Psychol Med 2001, 31(1):181.

22. Haddad M, Menchetti M, Walters P, Norton J, Tylee A, Mann A: Clinicians' Attitudes to depression in Europe: a pooled analysis of depression attitude questionnaire findings. Fam Pract 2012, 29(2):121-130.

23. Payne F, Harvey K, Jessopp L, Plummer S, Tylee A, Gournay K: Knowledge, confidence and attitudes towards mental health of nurses working in NHS direct and the effects of training. J AdvNurs 2002, 40(5):549-559.

24. Naji SA, Gibb J, Hamilton RJ, Lawton K, Palin AN, Eagles JM: How ready are practice nurses to participate in the identification and management of depressed patients in primary care? Primary Care Mental Health 2004, 2:47-54.

25. Haddad M, Walters $P$, Tylee A: District nursing staff and depression: a psychometric evaluation of depression attitude questionnaire findings. Int J Nurs Stud 2007, 44(3):447-456.

26. Waller R, Hillam JC: Assessment of depression in older medical inpatients: practice, attitudes and the effect of teaching. Aging Ment Health 2000, 4:275-277.

27. Kerr M, Blizard R, Mann A: General practitioner and psychiatrists: comparison of attitudes to depression using the depression attitude questionnaire. Br J Gen Pract 1995, 45(391):89-92.

28. Sighinolfi C, Norcini Pala A, Casini F, Haddad M, Berardi D, Menchetti M: Adaptation and psychometric evaluation of the Italian version of the depression attitude questionnaire (DAQ). Epidemiol Psychiatr Sci 2012, 8:1-8.

29. Statistical Package for the Social Sciences (SPSS): SPSS statistics, version 15.0.1. Chicago, IL: SPSS Inc; 2006.

30. Andersson SJ, Troein M, Lindberg G: Conceptions of depressive disorder and its treatment among 17 Swedish GPs. A qualitative interview study. Fam Pract 2001, 18(1):64-70.

31. Barrett JE, Williams JW Jr, Oxman TE, Frank E, Katon W, Sullivan M, Hegel MT, Cornell JE, Sengupta AS: Treatment of dysthymia and minor depression in primary care: a randomized trial in patients aged 18 to 59 years. J Fam Pract 2001, 50(5):405-412. 
32. Bortolotti B, Menchetti M, Bellini F, Montaguti MB, Berardi D: Psychological interventions for major depression in primary care: a meta-analytic review of randomized control trials. Gen Hosp Psychiatry 2008, 30(4):293-302.

33. Poluzzi E, Motola D, Silvani De Ponti F, Vaccheri A, Montanaro N: Prescriptions of antidepressants in primary care in Italy: pattern of use after admission of selective serotonin reuptake inhibitors for reimbursement. Eur J Clin Pharmacol 2004, 59(11):825-831.

34. Robinson DW, Geske JA, Prest LA, Barnacle R: Depression treatment in primary care. J Am Board Fam Pract 2005, 18:79-86.

35. Oyama O, Burg MA, Fraser K, Kosch SG: Mental health treatment by family physicians: current practices and preferences. Fam Med 2012, 44(10):704-711.

36. Layard R: The case for psychological treatment centres. BMJ 2006, 332(7548):1030-1032.

37. Wolf NJ, Hopko DR: Psychosocial and pharmacological interventions for depressed adults in primary care: a critical review. Clin Psychol Rev 2008, 28(1):131-161.

38. Hegel MT, Dietrich AJ, Seville $J$, Jordan CB: Training residents in problem-solving treatment of depression: a pilot feasibility and impact study. Fam Med 2004, 36(3):204-208.

39. Bertakis KD, Helms LJ, Callahan EJ, Azari R, Robbins JA: The influence of gender on physician practice style. Med Care 1995, 33(4):407-416.

40. Browne MO, Lee A, Prabhu R: Self-reported confidence and skills of general practitioners in management of mental health disorders. Aust J Rural Health 2007, 15:321-326.

41. Probst JC, Laditka SB, Moore CG, Harun N, Powell MP, Baxley EG: Rural-urban differences in depression prevalence: implications for family medicine. Fam Med 2006, 38(9):653-660.

42. Scholle SH, Gardner W, Harman J, Madlon-Kay DJ, Pascoe J, Kelleher K: Physician gender and psychosocial care for children: attitudes, practice, characteristics, identification, and treatment. Med Care 2001, 39(1):26-38

43. Roter DL, Hall JA, Aoki Y: Physician gender effects in medical communication: a meta-analytic review. JAMA 2002, 288(6):756-764.

44. Levinson W, Lurie N: When most doctors are women: what lies ahead? Ann Intern Med 2004, 141(6):471-474.

45. Fantini MP, Carretta E, Mimmi S, Belletti M, Rucci P, Cavazza G, Di Martino M, Longo F: L'impatto delle caratteristiche e dell'organizzazione dei MMG sulla qualità assistenziali delle malattie croniche. Mecosan 2010, 73:73-93.

46. David J, Danielle C, Sharon P, Kim W: Attitudes and practices of general practitioners training to work with drug-using patients. Drug Alcohol Rev 1999, 18(3):287-291.

47. Minter RM, Gruppen LD, Napolitano KS, Gauger PG: Gender differences in the self-assessment of surgical residents. Am J Surg 2005, 189(6):647-650

48. Sammer CE, Lykens K, Singh KP: Physician characteristics and the reported effect of evidence-based practice guidelines. Health Serv Res 2008, 43(2):569-581.

49. Meredith LS, Cheng WJ, Hickey SC, Dwight-Johnson M: Factors associated with primary care clinicians' choice of a watchful waiting approach to managing depression. Psychiatr Serv 2007, 58(1):72-78.

50. Rambelomanana S, Depont F, Forest G, Hebert G, Blazejewski S, Fourrier-Reglat A, Molimard M, Moore N: Antidepressants: general practitioners' opinions and clinical practice. Acta Psychiatr Scand 2006, 113(6):460-467.

51. Di Giuseppe PP, Fassone G, Biondi M, Ferrigno L, Mazzotti E, Pasquini M, Pasquini P: Treatment of major depressive disorder in primary care in Rome, Italy. Ann Ist Super Sanita 1998, 34(4):469-472.

52. Balestrieri M, Marcon G, Samani F, Marini M, Sessa E, Gelatti U, Donato F: Mental disorders associated with benzodiazepine use among older primary care attenders-a regional survey. Soc Psychiatry Psychiatr Epidemiol 2005, 40(4):308-315.

doi:10.1186/1471-2296-14-75

Cite this article as: Casini et al:: Primary care Physicians' perspective on the management of anxiety and depressive disorders: a cross-sectional survey in Emilia Romagna Region. BMC Family Practice 2013 14:75.

\section{Submit your next manuscript to BioMed Central and take full advantage of:}

- Convenient online submission

- Thorough peer review

- No space constraints or color figure charges

- Immediate publication on acceptance

- Inclusion in PubMed, CAS, Scopus and Google Scholar

- Research which is freely available for redistribution

Submit your manuscript at www.biomedcentral.com/submit
C Biomed Central 